\title{
TWO TRACE INEQUALITIES FOR OPERATOR FUNCTIONS
}

\section{Trung Hoa Dinh, Minh Toan Ho, Cong Trinh Le And Bich Khue Vo}

Abstract. In this paper we show that for a non-negative operator monotone function $f$ on $[0, \infty)$ such that $f(0)=0$ and for any positive semidefinite matrices $A$ and $B$,

$$
\operatorname{Tr}((A-B)(f(A)-f(B))) \leqslant \operatorname{Tr}(|A-B| f(|A-B|)) .
$$

When the function $f$ is operator convex on $[0, \infty)$, the inequality is reversed.

Mathematics subject classification (2010): 46L51, 47A30.

Keywords and phrases: Unitarily invariant norms, trace inequalities, operator monotone functions, operator convex functions.

\section{REFERENCES}

[1] T. Ando, Comparison of norms $\||f(A)-f(B)|\|$ and $\||f(|A-B|)|\|$, Mathematische Zeitschrift, 197, 3 1988, 403-409.

[2] K. M. R. Audenaert, J. Cals amiglia, L. I. Masanes, R. Munoz-Tapia, A. Acin, E. Bagan And F. Verstraete, Discriminating States: The Quantum Chernoff Bound, Phys. Rev. Lett., 98 (2007), 160501.

[3] E. A. CARlen, Trace inequalities and quantum entropy: An introductory course, Contemporary Mathematics, 529 (2010), 73-140.

[4] M. M. Kharroubi, Contractivity results in ordered spaces. Applications to relative operator bounds and projections with norm one, Math. Nachr., 290,(11-12) (2017), 1732-1752.

[5] É. RICARD, An inequality in noncommutative $L_{p}$-spaces, J. Math. Anal. Appl., 438, 1 (2016), 53-58.

[6] X. Zhan, Matrix inequalities, Springer-Verlag, Berlin, 2002. 